\title{
Difficulties in Inter-lingual Subtitling and the Strategies to Deal with: A Case Study of English Translation into Persian
}

\author{
Ahmad Ezzati Vazifehkhah ${ }^{1}$ \\ ${ }^{1}$ Collage of Foreign Language, Islamic Azad University, Shahr-e-Qods Branch, Tehran, Iran \\ Correspondence: Ahmad Ezzati Vazifehkhah, Collage of Foreign Language, Islamic Azad University, \\ Shahr-e-Qods Branch, Tehran, Iran. E-mail: ahmadezzate@yahoo.com
}

Received: January 11, 2017 Accepted: February 4, 2017 Online Published: February 9, 2017

doi:10.5539/ijel.v7n3p97

URL: http://dx.doi.org/10.5539/ijel.v7n3p97

\begin{abstract}
This paper examines the obstacles in translating inter-lingual subtitling, and then suggests some weighty theoretical strategies to deal with such difficulties from English translation into Persian. The present study makes an effort to analyze three main strategies such as deleting, condensing and adapting in the subtitling translation (Baker \& Saldanha, 2009). This study is a corpus-based, comparative, descriptive and non-judgmental analysis of English-Persian parallel corpus. Moreover, this research is comprised of English audio scripts of four American movies with Persian subtitles. The result indicates that Baker and Saldanha's proposed strategies are applicable, and the most frequent strategy is deleting at $53.47 \%$.
\end{abstract}

Keywords: deleting, condensing, adapting, Source Language (SL), Target Language (TL)

\section{Introduction}

Translation is one of the means of communication among human beings. Hence, translation Studies (TS), as a field of research took place over the recent years. Furthermore, searching on Audiovisual Translation (AVT) in TS as a new field is being increased. According to Diaz-Cintas (2005), "audiovisual translation refers to translation of products in which the verbal dimension is supplemented by elements in other media" (as cited in Hosseinnia, 2014). It is worthy to point out, Inter-semiotics has been known as a way to connect SL and TL. Further, inter-semiotics is a fairly new issue and is vastly used in communication rendering movies from SL to TL.

According to Hatim and Munday (2004), inter-semiotics is, "a method of language transfer used in translating types of mass audio-visual communication such as films and television" (p. 350). Consequently, inter-semiotics as a simple way to convey the message from SL to TL is being developed and improved further. Moreover, inter-semiotics as a pioneer on audiovisual translation has been distinguished in the most wide-spread forms of AVT as subtitling and dubbing.

According to Baker and Saldanha (2009), " Subtitling consists of the production of snippets of written text (subtitles, or captions in American English) to be superimposed on visual footage-normally near the bottom of frame - while an audiovisual text is projected, played or broadcast" (p. 14). "Hatim and Muday (2000) explained some constraints of subtitling and stated that there is a shift in mode from speech to writing and a result of this shift, some features of speech such as non-standard dialect, intonation, style shifting and turn taking could not be represented in written mode" (as cited in Mohseni \& Mozafar, 2013).

Further, Shuttleworth and Cowie (1997) have claimed that subtitling is the process of providing synchronized captions for films and television dialogues (p. 161). "Subtitles sometimes referred to as captions, are transcriptions of a movie or a TV dialogue in the same or different language, presented simultaneously on the screen at the bottom" (Cintas, 2008, p. 7).

However, what made subtitling different are technical and contextual aspects. Gottlieb (1992) uses various terminologies. He does believe "a subtitler is faced with formal (quantitative) and textual (qualitative) aspects. He also mentioned textual aspects are those imposed on the subtitles by the visual context of the film, whereas formal aspects are the space factors and the time factors" (as cited in Spanakaki, 2007). This originates in the fact that, it seems to be impossible to separate movies and modern life. That is why Baker (2004) has been claimed "Movie is so important that it has become the first arts of human world" (p. 40). 


\subsection{Hypothesis}

In light of the discussion exhibited in the introduction above, the present research provides the following hypothesis:

- Translation of subtitles from English language into Persian language is very challenging.

- Attempts to render English language into Persian subtitle will feature several translation strategies.

- Deleting, condensing and adapting are applicable subtitle strategies.

The above hypotheses draw upon the blurry image of subtitle strategies as they have not been made crystal clear to subtitlers. Moreover, this study aspires to clarify the concept of difficulties in inter-lingual subtitling in Persian language and presents three main strategies in order to help subtitlers.

\subsection{Research Question}

There is a main research question, in this regard: How to recreate the same set of translation in a way that might convey exactly the same ideas of the original language.

\section{This Paper}

\subsection{Statement of the Problem}

The notion of subtitling strategies has gained more momentum and attention in the past. Different definitions and classifications for subtitling strategies indicate that strategies are vibrant and convey the relevant concept in translation. Further, idioms, expressions and even culture specific-items face subtitlers to problems. As a result, choose the best strategies are essential to convey the message from SL to TL.

\subsection{Significance of the Study}

Subtitling strategies are under-researched field of knowledge hence the significance of this study. Moreover, this research aims to investigate what those difficulties are in the process of interpreting and translating subtitle from English language into Persian. Besides, an attempt has been made to examine the strategies to deal with such difficulties.

\subsection{Method and Material}

This paper is a corpus-based analysis of the subtitling strategies and conducted on a descriptive procedure that carries an English-Persian parallel corpus of 842 frames. The corpus included 80 minutes of movie dialogues in English and 80 minutes of Persian subtitles. 20 minutes of each movie was selected randomly. It is worthy to point out in order to obtain the required information; the researcher followed three certain steps: At first viewing the movies and put them under the close scrutiny, second transcribing the English utterances and comparing them with the Persian subtitles and finally, determining the used strategies based on aforementioned framework. Here is the list of four American movies:

\section{Kick Boxer: Vengeance (2016) by John Stockwell}

2. Never back down: No surrender (2016) by Michael Jai White

3. Southpaw (2015) by Antoine Fuqua

4. She's the man (2006) by Andy Fickman

\section{Inter-lingual Subtitling}

Traditionally, there existed two types of subtitling, inter lingual and intra lingual subtitling. Dìaz Cintas defined inter lingual subtitling as a way to convey the message from SL to TL and intra lingual as a way to keep the SL linguistic form (Anderman \& Rogers, 2003, p. 199). Based on Baker and Saldanha (2009), "Inter lingual subtitles provide viewers with a written rendition of the source text speech, whether dialogue or narration, in their own language" (p. 14).

Without any doubt, one of the most significant reasons of development of the movies dues to the essence of inter-lingual subtitling. As a facilitator, it helps the source language to be understandable in target one. Therefore, movies are vastly developed and extended to the other countries. The pivotal role of translation in inter-lingual subtitling would be more brilliant since any movie which is rendered by a translator, ought to convey some messages and ignore or at least changes some certain words or expressions. At the same time, any movie is a representation of its country and subsequently the culture. As a result, it exacerbates the undeniable role of translator in choosing the closest equivalence to transfer the message.

The mentioned point means two cultures in some circumstances are not identical. Based on Gonzalez (2004), 
"the difficulty in decoding cultural signs can be more problematic for the translator than semantic or syntacmatic difficulties" (as cited in Fathi and Moghimizadeh, 2014). In order to come over such difficulties there are three certain strategies. According to Baker and Saldanha (2009) they believed, deleting, condensing and adapting the source speech are some of the most common subtitling and used STRATEGIES deployed by professional translators (p. 16).

Moreover, Hatim and Mason (1990) suggested four stages to deal with such difficulties. The first is Identification of a source system semiotic entity. The second one is international core (a suitable TL denotation equivalent). The stage three is related to explication in detail. And final stage is the transformation of data (pp. 105-106). This research tries to investigate three main strategies to deal with difficulties in inter-lingual subtitling that are as following:

\subsection{Deleting}

One of the main difficulties in the translation of subtitles is the lack of Culture Specific-Items (CSI) from source language into target language. In such a circumstance, the best strategy to come over such difficulty is deleting or omission. Baker (2011) suggested that this strategy may sound rather affective, and actually it does no harm to omit translating a word or expression in some context (p. 42). It is clear that, through this strategy, the meaning is not distorted and just unimportant parts will be omitted. Hatim and Munday (2004) defined the omission as "Deliberate, or accidental, absence of a ST element or aspect of sense in the TT" (p. 345).

Moreover, Baker (1992) has claimed that as with single words, an idiom or expression may sometimes be omitted altogether in the target text. This may be because it has no close match in the receptor language, its meaning cannot be easily paraphrased or for stylistic reasons (p. 77). Also, she pointed out, "The change in the information content of the message may be in the form of omitting information specified in the source text. If the target language lacks a grammatical category which exists in the source language, the information expressed by that category may have to be ignored" (as cited in Hosseinnia, 2014).

According to Ivacovoni (2009), deleting or omission means dropping a word or words from the SL into TL while translating. This procedure could be the outcome of the cultural clashes that exist between the source language and the target language. Actually, it is in subtitling translations where omission attains its peak in use. Therefore, the translator omits words that do not have equivalents in the target text, or that may raise the hostility of the receptor. Further, Baker (2011) has pointed out that strategy involves rendering only the literal meaning of an idiom or expression in a context that allows for a concrete reading of an otherwise playful use of language (p. 84).

She added that if the meaning conveyed by a particular item or expression is not necessary enough to the development of the text to convince distracting the reader with the lengthy explanation, translators can and often do simply delete or omit translating the word or expression in question (p. 42). Moreover, Davies (2003) said, "omit a problematic CSI altogether, so that no trace of it is found in the translation" (as cited in Jaleniauskiene \& Cicelyte, 2009).

\subsubsection{Types of Omissions}

Generally speaking, based on Baker (2011), omission might have three forms: 1. Omission in an idiom that refers to contextual point of view, 2.Omission in the content of information that in a case of deleting does not injure the message, and 3.Omission in word or expression which concentrates on lexical aspect of a language (pp. 40-42). As a result, when a translator could not transfer or covey the CSI from source language into target one, the best strategy would be deleting.

\subsubsection{Different Types of Omission in a Sight}

In word or expression

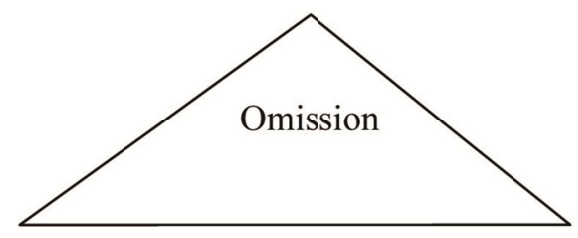

In an idiom

In the content of information 


\subsection{Condensing}

Due to differences between the source language and the target language, the concepts and meaning vary across these two. The most obvious point of difference appears through the culture-specific items which lead to the wrapped items by complexity when transferring the message from one language into another. In such a case, a translator reduces the length and the complexity of the given item. Hence, another strategy to come over such difficulty in subtitling is condensing. Through this strategy a translator tries to convey the message with fewer words.

According to Gottlieb (1997), condensation would seem to be typical strategy used, that is, the shortening of the text in the least obtrusive way possible. Furthermore, he added occasionally the translator has to make use of the condensation strategy. This strategy can be consequence of the reading ability of the receiver as well as caused by the limitations of the medium. Condensation is a shortened expression with an adequate content (p. 75). One of the main factors through the mentioned issue is the submitted translation should be coherent; otherwise, translation might be enigmatic or distorted.

\subsection{Adapting}

It is commonly accepted that translators mediate among cultures. This mediation includes ideological and linguistic aspects of a language. Hence, the audiovisual translation as a new field plays a basic role to convey the message from the source language into the target language. However, due to the different cultural background, it is not an easy job to find the equivalents in the target language. In such a case, translators adapt the items from the source language into the target language.

Based on Baker and Saldanha (2009), adaption is sometimes regarded as a form of translation which is characteristic of especial genres, most notably DRAMA (p. 4). Moreover, they added "Adaptation may be understood as a set of translative interventions which result in a text that is not generally accepted as a translation but is nevertheless recognized as representing a source text" (p. 3). In Vinay and Darbelnet's (1958) list of translation procedures, adaptation took place as a certain modifier of cultural reference for the target text readership (Hatim \& Munday, 2004, p. 334).

Furthermore, Baker and Saldanha (2009) have divided adaptation into two main types: local adaptation which is caused by problems arising from the original text itself and limited to certain parts of it, and global adaptation which is determined by factors outside the original text and which involves a more wide-ranging revision (p. 5).

It is worthy to point out in subtitling translation any misinterpretation through cultural information conduct him to a great barrier to pose successful translation. Therefore, a translator is supposed to adapt the cultural context to figure out the appropriate meaning and lead viewers to get the message easily. However, a translator should avoid a complete translation on special cultural context. The main reason is they lead subtitling too long and get viewers frustrated.

\section{Results and Discussion}

This section concentrates on the quantitative analysis of the corpus. In this regard, an attempt is made to reflect the frequency and percentage. Moreover, descriptive tables were presented for every movie in the study. Hence, Table 1 indicates the frequency and percentage of five certain inter lingual subtitling strategies on the four movies. This originates in the fact that Table 2 clarifies the total frequency and percentage which made use of four movies.

Table 1. Frequency and percentage of five certain inter lingual subtitling strategies on the four movies

\begin{tabular}{|c|c|c|c|c|c|}
\hline Strategies & & Kick Boxer & Never back down & Southpaw & She is the man \\
\hline \multirow[t]{2}{*}{ Omission in idiom } & Frequency & 1 & 3 & 0 & 2 \\
\hline & Percentage & $4.2 \%$ & $6 \%$ & $0 \%$ & $12.5 \%$ \\
\hline \multirow{2}{*}{$\begin{array}{l}\text { Omission in content of } \\
\text { information }\end{array}$} & Frequency & 2 & 8 & 1 & 3 \\
\hline & Percentage & $8.3 \%$ & $16 \%$ & $9.1 \%$ & $18.75 \%$ \\
\hline \multirow{2}{*}{$\begin{array}{l}\text { Omission in word Or } \\
\text { expression }\end{array}$} & Frequency & 6 & 16 & 6 & 6 \\
\hline & Percentage & $25 \%$ & $32 \%$ & $54.54 \%$ & $37.5 \%$ \\
\hline \multirow[t]{2}{*}{ Condensing } & Frequency & 6 & 6 & 0 & 2 \\
\hline & Percentage & $25 \%$ & $12 \%$ & $0 \%$ & $12.5 \%$ \\
\hline \multirow[t]{2}{*}{ Adapting } & Frequency & 9 & 17 & 4 & 3 \\
\hline & Percentage & $37.5 \%$ & $34 \%$ & $36.36 \%$ & $18.75 \%$ \\
\hline
\end{tabular}


Table 2. Total frequency and percentage of three main strategies on the four movies

\begin{tabular}{lll}
\hline Types of strategies & Total number & Percentage \\
\hline Deleting & 54 & $53.47 \%$ \\
Condensing & 14 & $13.86 \%$ \\
Adapting & 33 & $32.67 \%$ \\
\hline
\end{tabular}

The analysis of the data gathered in the present research revealed that translators have applied three mentioned strategies to convey the message from the source language into the target one. As it was indicated through table 2, 'Deleting' constituted the main part, i.e., 53.47\% of strategies in this research. Moreover, statistical results indicate that translators concentrate firstly on deleting. It is worthy to point out lacking appropriate equivalences lead translators to utilize this strategy in inter lingual subtitling.

Subsequently, 'Condensing' was used in $13.86 \%$ of addressed strategies, although, condensing did not have stable position of the whole corpus. It indicates the hierarchy usage of this strategy completely depends on some particular conditions such as intimacy among actors or actresses. Moreover, there were two main reasons which made translators use such strategy; first due to the space limitation and second quick appearance and disappearance of frames. However, the corpus analysis has shown no important elements were deleted in the four movies.

In the final stage, 'Adapting' formed $32.67 \%$ of the overall strategies. The number of adaptation traced in the corpus was low. It was used in some particular cases of untranslatable idioms, expressions or the content of information. This was not because of the lacking mentioned items in the target language, but because these items follow various meaning that could not be matched from the SL into the TL. Therefore, translators chose this strategy to keep the message and do not deviate minds of viewers.

In order for shedding light on the subject, Figure 1 presented to indicate the precise frequency of each strategy in the corpus; in addition, Figure 2 shows them totally.

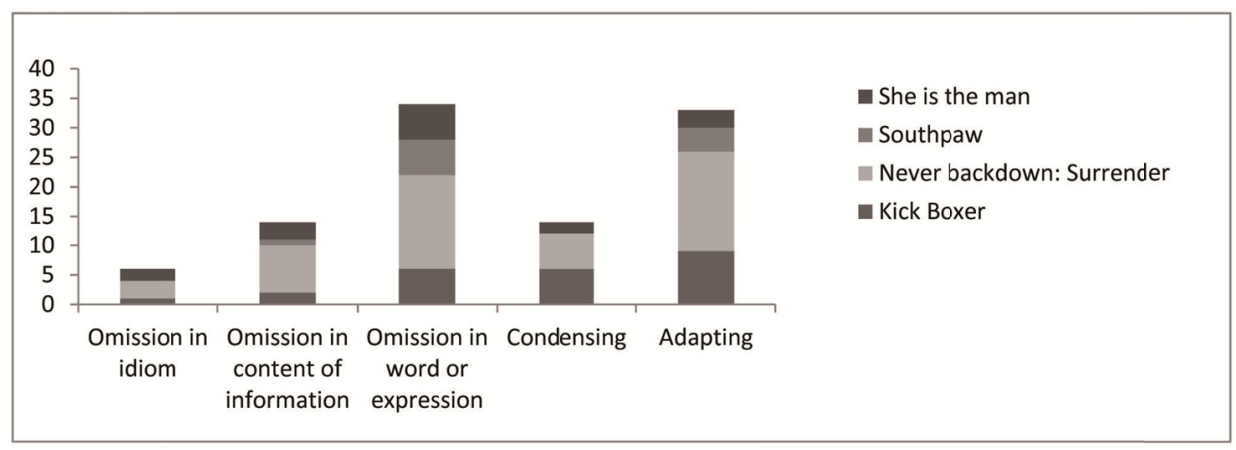

Figure 1. Frequency of five certain inter lingual strategies on the four movies

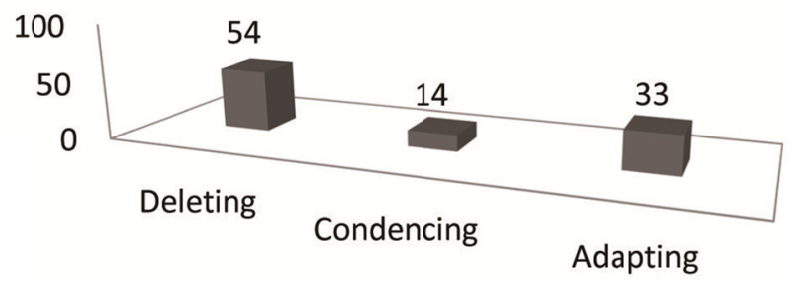

Figure 2. Total frequency of three main strategies on the four movies

\section{Conclusion}

Throughout different parts of paper, it shown that all the strategies proposed by Baker and Saldanha (2009) were used in the English-Persian subtitling. Hence, the result of the analysis of these strategies revealed that the most used one with a distinguishably high rate of occurrence is deleting at $53.47 \%$. It is worthy to point out in the case of street talks, deleting was much more frequent than the others. Further, adapting has received the next highest 
frequency, that is, $32.67 \%$. Finally, condensing is used $13.86 \%$ of overall addressed strategies in this study. In addition in the final stage, analyses showed that the used strategies by translators were not distributed equally among four movies. Another key concept is culture-specific items which should be considered by translators.

\section{References}

Baker, M. (2004). Routledge Encyclopedia of Translation Studies. Shanghai: Shanghai Foreign Language Education Press.

Baker, M. (2011). In Other Words: A Course Book on Translation. London and New York: Routledge.

Baker, M., \& Saldanha, G. (2009). Routledge Encyclopedia of Translation Studies. London and New York: Routledge.

Cintas, J. D. (2008). The Dictionary of Audiovisual Translation. Amsterdam and Philadelphia: John Benjamins. https://doi.org/10.1075/btl.77

Fathi, M., \& Moghimizadeh, R. P. (2014). An Analysis of English Subtitling of Verbal Cultural Signs in the 'A Separation' Iranian Film. International Journal of English and Education, 3(3).

Gottlieb, H. (1997). Subtitles, Translation and Idioms. University of Copenhagen, Copenhagen.

Hatim, B., \& Mason, I. (1990). Discourse and the Translator. Harlow, England: Longman.

Hatim, B., \& Munday, J. (2004). Translation: An Advance Resource Book. London and New York: Routledge.

Hosseinnia, M. (2014). Omission as a Strategy in Subtitling. International Journal of Language Learning and Applied Linguistics World, 5(1), 394-402.

Ivacovoni, A. (2009). Translation by Omission.

Mohseni, A., \& Mozafari, H. R. (2013). Strategies Employed in Translation of Idioms in English Subtitles of Two Persian Television Series. Journal of Language and Translation, 3(6), 27-32.

Shuttleworth, M., \& Cowie, M. (1997). Dictionary of Translation Studies. London: St. Jerome Publishing Company.

Spanakaki, K. (2007). Translating Humor for Subtitling. Translation Journal.

Yin, L. (2009). On the Translation of English Movie Titles. Asian Social Science, 5(3). https://doi.org/10.5539/ass.v5n3p171

\section{Copyrights}

Copyright for this article is retained by the author, with first publication rights granted to the journal.

This is an open-access article distributed under the terms and conditions of the Creative Commons Attribution license (http://creativecommons.org/licenses/by/4.0/). 